\title{
Development assistance for health: what criteria do multi- and bilateral funders use?
}

\author{
TRYGVE OTTERSEN* \\ Department of Global Public Health and Primary Care, University of Bergen, Bergen, Norway \\ Department of International Public Health, Norwegian Institute of Public Health, Oslo, Norway \\ Oslo Group on Global Health Policy, Department of Community Medicine and Global Health and Centre for Global \\ Health, University of Oslo, Oslo, Norway \\ APARNA KAMATH \\ Harvard T.H. Chan School of Public Health, Harvard University, Boston, Massachusetts, USA \\ SUERIE MOON \\ Harvard T.H. Chan School of Public Health, Harvard University, Boston, Massachusetts, USA \\ LENE MARTINSEN \\ Department of International Public Health, Norwegian Institute of Public Health, Oslo, Norway \\ JOHN-ARNE RØTTINGEN \\ Harvard T.H. Chan School of Public Health, Harvard University, Boston, Massachusetts, USA \\ Department of Health Management and Health Economics, University of Oslo, Oslo, Norway \\ Infectious Disease Control and Environmental Health, Norwegian Institute of Public Health, Oslo, Norway
}

\begin{abstract}
After years of unprecedented growth in development assistance for health $(\mathrm{DAH})$, the system is challenged on several fronts: by the economic downturn and stagnation of DAH, by the epidemiological transition and increase in non-communicable diseases, and by the economic transition and rise of the middle-income countries. This raises questions about which countries should receive DAH and how much, and, fundamentally, what criteria that promote fair and effective allocation. Yet, no broad comparative assessment exists of the criteria used today. We reviewed the allocation criteria stated by five multilateral and nine bilateral funders of DAH. We found that several funders had only limited information about concrete criteria publicly available. Moreover, many funders not devoted to health lacked specific criteria for DAH or criteria directly related to health, and no funder had criteria directly related to inequality. National income per capita was emphasised by many funders, but the associated eligibility thresholds varied considerably. These findings and the broad overview of criteria can assist funders in critically examining and revising the criteria they use, and inform the wider debate about what the optimal criteria are.
\end{abstract}

*Correspondence to: Trygve Ottersen, Department of Global Public Health and Primary Care, University of Bergen, PO Box 7804, 5020 Bergen, Norway. Email: trygve.ottersen@medisin.uio.no 


\section{Introduction}

The past two decades have witnessed an unprecedented growth in development assistance for health (DAH). Disbursements by bilateral, multilateral and other donors increased from \$7 billion in 1990 to \$34 billion in 2010 (2015 \$US) [Institute for Health Metrics and Evaluation (IHME), 2016]. In the 'golden age' between 2000 and 2010 , the annual growth rate was more than $11 \%$ in average, and DAH grew almost three times faster than development assistance to non-health sectors (IHME, 2016). Now, however, the DAH system is challenged on several fronts. One challenge is the economic downturn and stagnation of DAH, with only $1.2 \%$ in average annual growth since 2010 (IHME, 2016). Another challenge is the epidemiological transition and the triple burden of disease that many countries are facing today (Frenk et al., 2011; Frenk and Moon, 2013). New challenges, and opportunities, for the DAH system are also emerging with the economic transition and the rise of middle-income countries (MICs). The MIC category now comprises 105 countries (fiscal year 2015), $70 \%$ of the world's population, over $30 \%$ of the global gross domestic product (GDP), over $75 \%$ of the world's poor, and almost $70 \%$ of the disease burden in the world (Sumner, 2012) (based on data from the World Bank and the IHME).

These transitions raise questions about which countries should receive DAH and how much, and, fundamentally, which criteria promote fair and effective allocation of DAH across countries. The weight of this question is now being increasingly appreciated, as indicated by the recent Equitable Access Initiative (EAI, 2015). This initiative was led by the Global Fund to Fight AIDS, Tuberculosis and Malaria (GF) and eight co-conveners, with the aim of developing a new framework to classify countries and guide global health investments. The initiative recommended the use of a multi-criterion framework that takes into account income levels and health needs, in addition to domestic capacity and policies, where relevant (EAI, 2016).

In the search for the best allocation policy, an understanding of the criteria used by major funders of development assistance can provide a valuable basis. A good understanding of these criteria is also relevant for the many new global financing mechanisms that have been proposed (Ooms et al., 2006; CEWG, 2012; Moon and Omole, 2013; Gostin, 2014; OWG, 2014). Over the recent years, we have started to get better grip on the range of allocation criteria currently used for DAH (Salvado and Walz, 2013; Burgett et al., 2016), but we still lack an in-depth broad comparative review focussing on these criteria. ${ }^{1}$

The objective of this paper is to provide a broad comparative overview of the allocation criteria stated by major funders of DAH. We reviewed the policy documents made readily available to the public, and we communicated directly with the funders on points in need of clarification. In this article, we first categorise allocation criteria for development assistance, next examine the criteria stated by

1 This article is based on a 2014 working paper for the Chatham House Centre on Global Health Security (Ottersen et al., 2014). 
bilateral and multilateral funders, and finally consider similarities and differences among the criteria.

\section{Allocation criteria and analytical framework}

Allocation criteria, of the kind addressed here, guide the allocation of DAH across countries. Every funder of DAH employs some allocation criteria, but these are not necessarily explicit. Under a broad understanding of 'allocation criteria', these include criteria for deciding what countries are eligible for assistance, criteria for determining how much assistance each country will be offered, and criteria for setting the levels of co-financing required of recipients (Fan et al., 2014). Particular attention is often paid to eligibility criteria as these typically apply early in the allocation process, are binary (i.e. countries are eligible or not), and are linked to a necessary condition for receiving funding.

Explicit criteria have a number of advantages (Daniels and Sabin, 2008). Compared with implicit ones, explicit criteria tend to better facilitate transparency, accountability and public deliberation. These effects are valuable in themselves, but they are also likely to promote the development of better criteria. Moreover, explicit and especially quantitative criteria may improve the consistency of funding decisions, increase predictability and support the coordination of DAH allocations and contributions. Several of these benefits may materialise even when funders set up criteria ad hoc to fit certain decisions they would like to make in the future. At the same time, the criteria stated by the funders may only partly guide actual decisions. Especially for bilateral donors, a range of other, often political and trade-related considerations are likely to influence the final outcomes of the allocation process (Berthelemy, 2006; Vázquez, 2015).

When identifying, examining and comparing criteria, it is useful to have a framework for analysis. Most criteria used by the major providers of DAH can be seen as members of one of two categories: need criteria and effectiveness criteria. Need criteria can overlap significantly with what are called 'equity criteria' (Guillaumont, 2008).

\section{Need criteria}

Need criteria dictate that aid is to be allocated to countries with the greater need. Most often, need is understood to decrease with the current or projected level of development or some other outcome of interest (Anderson, 2008; Leo, 2010; Basu et al., 2014). Candidate indicators are, for example, gross national income per capita (GNIpc), the Human Development Index (HDI), life expectancy at birth, under-five mortality rate (U5MR) and burden of disease.

Need for assistance can also be understood in terms of the country's capacity to address domestic challenges and further develop without aid - the lower that capacity, the greater the need (Knack et al., 2012; Resch et al., 2015). So understood, 
'capacity need' can be distinguished from 'development need' of the kind described above. GNIpc is a commonly used indicator for economic capacity, either directly or through the World Bank income classification of countries. For the fiscal year 2015, countries with GNIpc $\leqslant \$ 1045$ in 2013 are classified as low-income countries (LICs); countries with GNIpc $\$ 1046-4125$ and $\$ 4126-12,745$ as lower- and upper-middle income countries (LMICs and UMICs), respectively; and countries with GNIpc $\geqslant \$ 12,746$ as high-income countries (HICs) (World Bank, 2016a).

\section{Effectiveness criteria}

According to effectiveness criteria, aid is to be allocated to where it will be more effective. Effectiveness can be defined as increasing with the health gain, such as a reduction in U5MR, or some other desired outcome from the intervention in question (Pietschmann, 2013; Cagé, 2015). If one consider the effectiveness of a given amount $\mathrm{DAH}$, effectiveness overlaps with common understandings of cost-effectiveness and efficiency. 'Effectiveness' can also overlap with 'expected impact', 'performance' and 'absorptive capacity' in several different ways, depending on the terminology used.

Need criteria are often complemented with effectiveness criteria because assistance to those most in need is not necessarily the most effective use of resources and is sometimes very ineffective. This may be the case, for example, with so-called failed states (McGillivray, 2011). Conversely, effectiveness criteria is usually insufficient alone because most people not only care about the sum total of benefits, but also how badly off those who receive the benefits are.

Specific effectiveness criteria rarely refer directly to a comprehensive metric of development, partly because the information needed is not directly available. Instead, effectiveness criteria typically refer to an indicator of expected effectiveness which may pertain to demonstrated improvements in the past or to a country characteristic perceived to correlate with the effectiveness of aid (Pietschmann, 2013; Cagé, 2015). The former may include past reduction in U5MR or past improvement in vaccine coverage, and the latter may include high institutional quality and low level of corruption.

\section{Cross-cutting criteria}

Some criteria have little direct relation to the need and effectiveness categories or substantially relate to both. Examples include criteria related to population size, expected aid from other donors, and universality or equality in aid shares among countries, as well as criteria emphasising the distinction between a country's effort and circumstances (Llavador and Roemer, 2001; Cogneau and Naudet, 2007). There is also a distinction - particularly relevant to bilateral DAH - between criteria primarily related to donor interest and criteria primarily related to recipient need (Berthelemy, 2006).

Criteria that relate substantially to both need and effectiveness may relate to the two in the same way or in opposing ways. Poor quality of policy and governance may decrease the effectiveness of aid, but at the same time increase the need for aid 
due to lower domestic capacity for making progress without external assistance (McGillivray, 2011). In contrast, criteria linked to economic structural vulnerability may harbour no conflict between need and effectiveness. This is suggested by the claim that vulnerability so defined increases need, but also represents a situation in which at least some kinds of aid may be particularly effective (Guillaumont, 2008). Where the two are perceived to go together, need is sometimes used as a proxy for effectiveness.

Finally, many allocation criteria involve some form of conditionality (Gibson et al., 2005; Koeberle et al., 2005; Temple, 2010). The intended purpose may primarily pertain to the effectiveness of aid, as is likely the case with many co-financing requirements. But conditionality may also be motivated by the wish to target DAH towards the most needy subpopulations or for other, more political reasons.

\section{Criteria stated by multilateral funders}

Alongside the World Health Organisation (WHO), the top four multilateral funders of DAH are the GF; Gavi, the Vaccine Alliance (Gavi); the International Development Association (IDA); and the United Nations Children's Fund (UNICEF). In 2015, these channelled DAH amounting to 3.3, 1.6, 1.3 and 1.2 billion \$US, respectively (IHME, 2016). Table 1 summarises the criteria put forward by these four funders plus the United Nations Development Programme (UNDP), which is known to have a very explicit allocation formula.

Table 1. Allocation criteria explicitly emphasised by multilateral funders

\begin{tabular}{|c|c|c|c|c|c|c|}
\hline Metric & $\begin{array}{l}\text { Typical impact on } \\
\text { allocation }\end{array}$ & GF & Gavi & IDA & UNICEF & UNDP \\
\hline \multicolumn{7}{|l|}{ Criteria primarily related to need } \\
\hline GNI per capita & - & $\bullet$ & • & • & • & • \\
\hline Population size & + & & & - & - & - \\
\hline Disease burden & + & - & • & & & \\
\hline U5MR & + & & & & - & \\
\hline Other sources of funding & $+1-$ & & & - & & \\
\hline Sub-Saharan Africa & + & & & • & • & \\
\hline LDCs & + & & & & • & • \\
\hline Key and vulnerable populations & + & - & & & & \\
\hline \multicolumn{7}{|l|}{ Criteria primarily related to effectiveness } \\
\hline Performance/impact & + & - & • & • & & \\
\hline Efficiency/value for money & + & • & - & & & \\
\hline \multicolumn{7}{|l|}{ Criteria primarily reflecting conditionality } \\
\hline Domestic co-financing & + & - & - & & & \\
\hline Domestic spending on immunisation & + & & • & & & \\
\hline
\end{tabular}

GNI = gross national income; GF $=$ The Global Fund to Fight AIDS, Tuberculosis and Malaria; Gavi = Gavi, the Vaccine Alliance; IDA = The International Development Association; UNICEF = United Nations Children's Fund; UNDP = United Nations Development Programme; U5MR = under-five mortality rate; $\mathrm{LDC}=$ least developed countries. 
The WHO and Bill \& Melinda Gates Foundation differ in nature from

the funders in Table 1 and were not examined. The European Commission is a major funder, but falls short of the four big ones, with DAH in 2015 amounting to 0.4 billion \$US, according to IHME estimates (IHME, 2016).

In both this and the subsequent section, emphasis is put on criteria related to initial allocations. These may differ from criteria related to renewals, adjustments and transition, although eligibility and transition criteria often are closely linked. Moreover, emphasis is put on the main features of the allocation schemes and many details, including most exceptions, are omitted. The aim was to describe, clarify and compare, not to judge whether the content of the criteria is good or bad. When comparing, it is important to note that the institutions are heterogeneous in their nature and in the kinds of allocations they make. For example, while GF and Gavi largely channel funds to disease-specific programmes implemented by others, UNICEF and UNDP partly allocate funds across their own country offices, which also act as implementers. The allocation criteria described are sought to reflect the funders' allocation policies as of June 2016.

\section{The Global Fund to Fight AIDS, Tuberculosis and Malaria (GF)}

GF is a public-private partnership concentrating on HIV/AIDS, tuberculosis and malaria. For the period 2017-2019, allocations are based on criteria sets related to eligibility, basic application requirements, technical merit and grant size.

The two primary eligibility criteria are GNIpc and disease burden (GF, 2016b). The GNIpc criterion is based on the World Bank income classification and utilises countries' average GNIpc over a three-year period. LICs and LMICs are eligible regardless of burden. UMICs are eligible if the burden from the disease in question is 'high', 'severe' or 'extreme', while HICs are ineligible. For these eligibility criteria and for several other parts of the allocation process, there are certain flexibilities for 'challenging operating environments', that is, countries or regions characterised by weak governance, poor access to health services, and manmade or natural crises (GF, 2016c).

For the application, there are requirements for focus and co-financing (GF, 2016d). LMICs have to focus at least $50 \%$ of the funding on key and vulnerable populations, 'highest impact interventions', or both. For UMICs, the requirement is $100 \%$. Co-financing requirements also vary with GNIpc and disease burden, and these requirements can be seen as a form of conditionality.

A review panel assesses the application focus and the technical merits of each application with the aim of ensuring that investments achieve the highest impact (GF, 2013, 2016e). The technical criteria are concerned with soundness of approach, feasibility, potential for sustainable outcomes and value for money.

For determination of grant size, an allocation formula is applied (GF, 2016f). The main criteria are again economic capacity or ability to pay (measured by GNIpc) and disease burden. After application of the formula, the Secretariat can 
make adjustments based on qualitative factors that may include major sources of external financing, minimum funding levels, willingness to pay, past programme performance and absorptive capacity, risk, increasing rates of new infections in lower prevalence countries, and populations disproportionately affected by HIV and tuberculosis, and in low-endemicity malaria settings. The GF Board has also opened up for adjustments for each disease to account for the needs of concentrated burdens in higher income settings (GF, 2016f). For example, specific estimates for key populations of people living with HIV may be used.

Apart from the funds distributed according to the allocation formula, significant funds are set aside for catalytic investments in strategic priorities, including for key and vulnerable populations, women and girls, human rights, multi-country approaches and strategic initiatives (GF, 2016f).

\section{Gavi, The Vaccine Alliance (Gavi)}

Gavi is a public-private partnership whose primary objective is to improve immunisation coverage in developing countries. Gavi's allocation process has three central stages (Gavi, 2015b): determination of eligibility to apply, assessment of applications and ranking of the recommended applications if Gavi funds are insufficient.

To be eligible, countries must have GNIpc equal to or below $\$ 1580$ in average over the past three years (Gavi, 2015c, 2016a). For new vaccine support and most vaccines, an additional eligibility criterion is that coverage for the third dose of the pentavalent vaccine against diphtheria, tetanus, pertussis, hepatitis $\mathrm{B}$ and Haemophilius influenzae type B (Penta 3 ) is equal to or above $70 \%$. In addition, a cofinancing requirement that depends on GNIpc applies to most vaccines.

A wide range of specific criteria is applied in the assessment of applications, and among these criteria is burden of disease (Gavi, 2015a). Available resources may be insufficient to fund all applications recommended by the application review committee. For such situations, Gavi has a specific prioritisation mechanism (Gavi, 2013, 2016b). This has not been frequently used because funding has been sufficient relative to applications, but it illustrates an explicit way of balancing concerns. The mechanism ranks applications according to an index motivated by the following four objectives and calculated from a corresponding set of four criteria:

- Maximise health impact: ratio of future deaths averted to total population from the first five years of vaccination;

- Maximise value for money: cost per future death averted;

- Reinforce financial sustainability: number of years for which a country has not fulfilled its co-financing commitment, and percentage of spending on vaccines used in routine immunisation financed with government funds;

- Support countries with the greatest need: GNIpc. 
These criteria are weighted $30,30,25$ and $15 \%$, respectively. The prioritisation mechanism includes also a fifth criterion, which operates as a constraint: when resources are scarce, a maximum of one application per country is funded per round. This is seen as a way to promote an equitable distribution across countries.

\section{International Development Association (IDA)}

IDA is the World Bank's main lending and grant mechanism for the poorest countries, and improving health is central to the bank's mission. The allocation process is very explicit and has two basic components: determination of eligibility and a performance-based allocation system (IDA, 2013; World Bank, 2016b).

To access IDA resources, a country must have a GNIpc below an annually updated threshold, which is $\$ 1215$ for the fiscal year 2016. In addition, the country must lack creditworthiness to borrow on market terms.

For the allocation across eligible countries, IDA employs what it calls a performance-based allocation (PBA) system. Central to this system is the PBA formula, which has three arguments: the IDA's Country Performance Rating (CPR), population size, and GNIpc. As the name of the formula suggests, country performance is intended to be the main determinant of allocations, and the CPR is supposed to capture determinants of aid effectiveness. For example, the formula assigns less aid to countries with institutions of low quality as aid is expected to be less effective in these settings. The CPR is based on the Country Policy and Institutional Assessment (CPIA) rating and the Portfolio Performance Rating (PPR). The CPIA consists of 16 criteria grouped into four clusters: (a) economic management; (b) structural policies; (c) policies for social inclusion and equity; and (d) public sector management and institutions. The PPR is supposed to reflect the health of the IDA projects portfolio and decreases with the percentage of problem projects in the country. Both CPIA and PPR ratings are done by World Bank staff. The CPR is calculated as follows:

$$
\mathrm{CPR}=\left(0.24 \mathrm{CPIA}_{\mathrm{A}-\mathrm{C}}+0.68 \mathrm{CPIA} \mathrm{D}+0.08 \mathrm{PPR}\right)
$$

where CPIA $A_{A-C}$ is the average ratings of CPIA clusters $A$ to $C$, and CPIA $A_{D}$ is the rating of CPIA cluster $\mathrm{D}$.

The CPR calculated is then used in a formula according to which country allocation increases with CPR and population size and decreases with GNIpc as follows:

$$
\text { IDA country allocation }=\mathrm{f}\left(\mathrm{CPR}^{4} \text {, population, } \mathrm{GNIpc}^{-0.125}\right)
$$

\section{United Nations Children's Fund (UNICEF)}

UNICEF is the UN organisation concentrating on the world's children, and improving their health is a core objective. UNICEF's system for the allocation of its regular resources for programs consists of an eligibility criterion, three core criteria and two distributional targets (UNICEF, 1997, 2012, 2016). Eligible 
countries are those that have not achieved high-income status, according to World Bank data and definitions. Beyond a minimum amount, allocations are based on three core criteria: U5MR, child population and GNIpc. More specifically, the allocation to a country tends to increase with U5MR and child population and decrease with GNIpc. Constraining the three criteria are two distributional targets, according to which at least 60 and $50 \%$ of the regular resources are to be allocated to least-developed countries (LDCs) and countries in sub-Saharan Africa, respectively.

\section{United Nations Development Programme (UNDP)}

UNDP is the UN's global development network, and health is central to its agenda. The annual level of regular programme resources (TRAC-1) available for an individual country is determined by eligibility criteria, an allocation formula and distributional targets.

Previously, GNIpc had to be at or below $\$ 5500$ for a country to be eligible (UNDP, 2012b). For 2014 and onwards, UNDP has adopted the World Bank high-income threshold to determine eligibility (UNDP, 2012a, 2013b).

Beyond a minimum amount, allocations are based on a formula that is basically the product of two weights related to GNIpc and population size, respectively (UNDP, 2011, 2012a). In the previous period, the GNIpc weight decreased with GNIpc at a decreasing rate from 9.31 at GNIpc of \$0 to 0.250 at GNIpc of \$1464 and then remained constant. The population weight increased with population size at a decreasing rate from 0.050 at 0 million to 6.450 at 1 billion and then remained constant. For the period 2014-2017, the weighting functions have been modified (UNDP, 2012a, 2013b), but the details are not yet publicly available. In any case, overall allocations must comply with the same distributive targets as before: LICs are supposed to receive between 85 and $91 \%$ of total resources, MICs between 9 and $15 \%$, and the cross-cutting category of LDCs at least $60 \%$ (UNDP, 2012a).

\section{Criteria stated by bilateral funders}

Of the $\$ 36.4$ billion of DAH provided in 2015, 33\% (\$12 billion) was disbursed by bilateral agencies (IHME, 2016). The criteria stated by nine major agencies of this kind are summarised in Table 2. These were selected based on the extent to which they represented countries providing large amounts of DAH - in absolute terms, per capita terms or both - and the extent to which a minimum of information about their criteria was readily available. At the same time, many bilateral funders channel a significant part of their assistance through multilateral institutions, and these funds will then be allocated according to the criteria used by that institution. 
Table 2. Allocation criteria explicitly emphasised by bilateral funders

\begin{tabular}{|c|c|c|c|c|c|c|c|c|c|c|}
\hline Metric & $\begin{array}{l}\text { Typical impact on } \\
\text { allocation }\end{array}$ & USAID & PEPFAR & MCC & DFID & BMZ & GAC & DFAT & Norad & LuxDev \\
\hline \multicolumn{11}{|l|}{ Criteria primarily related to recipient need } \\
\hline GNI per capita ${ }^{a}$ & - & & & - & & & & - & - & - \\
\hline HDI & - & & & & & & & & & - \\
\hline Disease burden & + & - & - & & & & & - & - & \\
\hline Need (unspecified) & + & - & & & . & - & - & & & \\
\hline \multicolumn{11}{|l|}{ Criteria primarily related to effectiveness } \\
\hline Effectiveness/impact & + & & - & - & - & & - & & & \\
\hline Performance & + & - & & - & & & & - & & \\
\hline $\begin{array}{l}\text { Good governance/policy environment (including transparency/ } \\
\text { democracy) }\end{array}$ & + & & & • & • & • & & & • & \\
\hline \multicolumn{11}{|l|}{ Other } \\
\hline Political/economic/linguistic/geographic linkages & + & - & & & - & - & - & - & & \\
\hline Human rights & + & & & - & - & - & & & - & \\
\hline Fragility/conflict & + & & & & • & - & & & - & \\
\hline
\end{tabular}

GNI = gross national income; HDI = Human Development Index; USAID = United States Agency for International Development; PEPFAR = United States President's Emergency Plan for AIDS Relief; MCC = Millennium Challenge Corporation (United States); DFID = Department for International Development (United Kingdom); BMZ = Federal Ministry for Economic Cooperation and Development (Germany); GAC = Global Affairs Canada; DFAT $=$ Department of Foreign Affairs and Trade (Australia); Norad = Norwegian Agency for Development Cooperation; LuxDev = Luxembourg Agency for Development Cooperation.

${ }^{a}$ Use of GNI per capita beyond indirect use through the OECD-DAC list of ODA recipients, which is centrally based on GNI per capita. LuxDev uses the HDI, of which GNI per capita is one part. 
United States Agency for International Development (USAID)

USAID is the United States' primary foreign assistance agency. Its global health programmes are geared towards addressing maternal and child health, HIV/AIDS, and other infectious diseases in developing countries (Department of State, 2014). One of USAID's nine principles of development and reconstruction assistance is 'selectivity', which calls for resources to be allocated on the basis of need, local commitment, and foreign policy interests (USAID, 2011). In the context of global health, allocation decisions primarily depend on the needs and on the commitment of the recipient government with respect to the specific programme issue at hand, rather than needs more generally (USAID, 2006). For example, resources for maternal and child health and HIV/AIDS may be allocated based on criteria such as disease severity and magnitude, while resources for family planning are concentrated in countries with the greatest unmet needs for family planning (USAID, 2006, 2014, 2015). In addition, allocations are often informed by previous programme performance (USAID, 2006).

\section{United States President's Emergency Plan for AIDS Relief (PEPFAR)}

PEPFAR is primarily focussed on combating HIV/AIDS. Country eligibility is based on the size and demographics of the population with HIV/AIDS and on lack of financial resources (US Congress, 2003, 2008; PEPFAR, 2011; Institute of Medicine, 2013). Specific criteria for the allocation of resources across eligible countries are not made readily available to the public. More generally, PEPFAR seeks to target geographic areas and populations where HIV/AIDS is most prevalent and in which it can achieve the greatest impact for its investments (PEPFAR, 2015).

\section{Millennium Challenge Corporation (MCC), United States}

MCC was established by the US Congress in 2004 as an independent foreign aid agency. MCC partners with poor countries, but only those committed to principles of good governance, economic freedom, and investment in their citizens (MCC, 2015c). MCC is very explicit about its allocation criteria, and it publishes its methodology and criteria for approval by Congress and public comment (MCC, 2016).

First-line candidacy for aid is restricted to those countries classified as LICs or LMICs by the World Bank (MCC, 2015a). Accordingly, to pass the candidacy test in the fiscal year 2016, GNIpc in 2014 had to be at or below $\$ 4125$.

Eligibility among the candidate countries is based on policy performance and the opportunity to reduce poverty and generate economic growth, as well as the funding available (MCC, 2015b). Policy performance is assessed using 20 third-party indicators in the categories of encouraging economic freedom, investing in people and ruling justly. To be eligible, a country must normally attain a score greater than the median score of its income group (LIC or LMIC) on at least half of the indicators, pass the control of corruption indicator and pass either 
the political rights or civil liberties indicator. Indicators gauged against an absolute threshold, rather than the median score, are those related to inflation, political rights, civil liberties, immunisation rates (LMICs only).

The assessment of the opportunity to reduce poverty and generate economic growth is somewhat less structured. However, central considerations will often pertain to governance, human rights, markets and MCC's own experience and ability to reduce poverty and generate economic growth in the country in question.

\section{Department for International Development (DFID), United Kingdom}

DFID leads the United Kingdom's work to end extreme poverty around the world. Eligibility has been based on recipient country need, expected effectiveness of aid, and strategic fit with UK government priorities, with the aim of prioritising countries where UK aid can make the greatest impact (DFID, 2011). In 2015, the UK government launched its new aid strategy (DFID, 2015). As part of this strategy, the government will direct more funding to fragile and conflict affected states and allocate at least $50 \%$ of DFID's budget to fragile states and regions. The government wants to do more to support a broader range of countries which are home to very large numbers of the world's poorest people, and it will also continue to drive development in regions where the United Kingdom has close ties, including strong historical, cultural and diaspora links. In allocating aid, the government will consider the fit with its strategic objectives, the level of need, the ability of partner countries to finance their own development, what support they get from others and their future risks, including humanitarian, economic and climate. Exactly how level of need will be assessed is yet not clear (UK Parliament, 2016).

\section{Federal Ministry for Economic Cooperation and Development (BMZ), Germany}

$\mathrm{BMZ}$ aims at reducing poverty, promoting equitable forms of globalisation, and building peace. Chief criteria for assessing eligibility for bilateral aid and the level of engagement are good governance and general conditions in the partner country, poverty and need, German interests and division of labour with other actors operating in the partner countries (BMZ, 2013). Other considerations relevant to the selection of countries are the human rights situation, relevance to global public goods, and particular treatment for fragile and post-conflict countries (BMZ, 2013, 2014).

\section{Global Affairs Canada (GAC)}

GAC is Canada's lead agency or development assistance. It primarily supports 25 focus countries. These were chosen on the basis of the countries' needs, their capacity to benefit from development assistance, and their alignment with Canadian 
foreign policy priorities (GAC, 2016). However, the way need and capacity to benefit is operationalised for the selection of countries is not readily available.

\section{Department of Foreign Affairs and Trade (DFAT), Australia}

The Australian Agency for International Development was integrated into DFAT in 2013. DFAT's stated aim for Australia's aid programme is to 'promote Australia's national interests by contributing to sustainable economic growth and poverty reduction' (DFAT, 2016). DFAT concentrates on countries in the Indo-Pacific region with the aim of targeting at least $90 \%$ of country programme aid in this region (DFAT, 2014). Correspondingly, DFAT's Health for Development Strategy focusses on Southeast Asia and the Pacific, and it does so in order to help protect Australia's health security and advance the economic and poverty objectives of the aid programme in the region (DFAT, 2015). As part of the strategy, a set of Australian aid policy tests are applied to health (DFAT, 2015). It is made clear that DFAT health diplomacy and investments will prioritise LICs and LMICs. Health needs does not appear to be an important criterion in itself, but it is indicated that one considerations is whether poor health is limiting partner countries' progress with economic growth and poverty reduction. At all levels, DFAT seeks to link funding to performance, and this includes rewarding partner governments that perform well with additional funding (DFAT, 2014).

\section{Norwegian Agency for Development Cooperation (Norad)}

Norad's mandate is to support poverty-reduction strategies around the world, and the Norwegian Ministry of Foreign Affairs is in charge of priority setting and country selection at the overarching level (Norad, 2014, 2016).

Up until 2014, Norway was providing bilateral aid to a large number of countries (116 in 2013). From 2015, the Norwegian Government has aimed to reduce the number of partner countries down to 84 (Ministry of Foreign Affairs Norway, 2014a). In addition, 12 focus countries where efforts will be particularly strengthened have been selected (Ministry of Foreign Affairs Norway, 2014a). In the selection process, the Government looked for LICs or LMICs with limited access to capital and expertise from sources other than aid, and with attention on human rights, democracy and strengthening of the private sector (Ministry of Foreign Affairs Norway, 2014b). One category of focus countries consists of six fragile countries, where stabilisation and peacebuilding are the central objectives. These countries are Afghanistan, Haiti, Mali, Palestine, Somalia and South-Sudan. The other category is countries currently undergoing a process of development, where efforts will be concentrated on the private sector and on resource and revenue management. These countries are Ethiopia, Malawi, Mozambique, Myanmar, Nepal and Tanzania. From 2017, the Norwegian Ministry of Foreign Affairs is 
planning to focus even more on fragile states due to the terrorism threat and the refugee situation (Ministry of Foreign Affairs Norway, 2016).

\section{Luxembourg Agency for Development Cooperation (LuxDev)}

LuxDev's mission is to eradicate poverty and ensure sustainable development in all spheres (LuxDev, 2015a). Assistance is concentrated in nine 'privileged partner countries', selected on the basis of their HDI value (LuxDev, 2013). The HDI integrates GNIpc, life expectancy and education. The privileged partner countries are Burkina Faso, Cape Verde, Mali, Niger, Senegal, Laos, Vietnam, El Salvador and Nicaragua (LuxDev, 2015b). More specific allocation criteria are not made readily available to the public.

\section{Comparison and implications}

\section{Transparency}

One clear finding from the review is that several funders only to a limited extent had made concrete criteria for eligibility and allocation across countries readily available to the public. This was particularly the case for the bilateral funders. The lack of explicit criteria is problematic from the perspective of transparency, accountability, learning and predictability (Daniels and Sabin, 2008; McGee, 2011; Moon and Omole, 2013). From this perspective, citizens in recipient countries and potential recipient countries should have access to information about criteria that can profoundly affect their health and well-being, while citizens in donor countries should have access to information about the use of their tax money. A commonly held ideal is also to have mechanisms in place that enable citizens and other stakeholders to challenge the criteria used and to provide input to revisions (Daniels and Sabin, 2008). Finally, transparency about the criteria used can help make DAH more predictable for recipient governments (Moon and Williamson, 2010). Against this background, there are good reasons for funders of DAH to critically examine the extent to which their allocation policy and practices comply with the now widely accepted standards for accountability.

Other funders had very concrete and explicit criteria, including GF, IDA and MCC. To the extent that funders were transparent about the specific criteria they use, important differences are displayed by Tables 1 and 2 . Several criteria were only used by one or some few funders, including the HDI based criterion used by LuxDev.

\section{Need $v$ s effectiveness}

Tables 1 and 2 further suggest that funders strike the balance between need and effectiveness differently. The eligibility criteria of GF, for example, seem to concentrate on need, as they emphasise GNIpc and disease burden. Likewise, UNICEF's allocation formula considers U5MR, child population and GNIpc. 
In contrast, IDA's allocation formula concentrates on effectiveness, to the extent that CPR is perceived as a useful proxy for this. While the concerns for need and effectiveness may point in the same direction, the trade-off between these two concerns is a fundamental issue for the allocation of DAH, especially from the perspective of normative theory (Brock, 2002; Anderson, 2008; Guillaumont, 2008). According to many of these theories, the size of benefits matters, but benefiting people matters more the worse off these people are. It is therefore important that funders of DAH carefully consider to what extent they will accept smaller gains for the sake of benefiting the worse off, make the choices explicit and design their criteria accordingly. Gavi's prioritisation mechanism illustrates how the trade-offs can be made explicit and modified: the objective 'maximize value for money' is given twice the weight of 'support countries with the greatest need' (Gavi, 2013, 2016b). Obviously, if it so wished, Gavi could tilt the balance towards needs by increasing the weight assigned to the latter criterion.

\section{Fragility and self-interest}

Funders also varied in focus in several other ways. In particular, some funders stressed that fragility and conflict is a key criterion in country selection (e.g. DFID and Norad), while other funders seemed to put no weight on such a criterion at all. The funders also differed greatly in the extent to which they were open about political interests or self-interest being a key criterion for eligibility and allocation across countries. DFID and DFAT, for example, were very open about this.

\section{Economic capacity}

One specific criterion was emphasised by many funders: GNIpc. This was done directly as part of World Bank's income classification, or both. In addition, LuxDev emphasised the HDI, which integrates GNIpc. Several funders also focused on countries on the OECD-DAC list of ODA recipients, which is centrally based on the World Bank's income classification and thus GNIpc. The use of a GNIpc criterion was particularly prominent in the determination of eligibility. However, the GNIpc threshold value, at or above which countries are deemed ineligible for aid, varied considerably: from \$1215 (IDA), via \$1580 (Gavi) and \$4125 (MCC), to more than $\$ 12,000$ for several other funders. In comparison, LICs and HICs are classified by the World Bank as having GNIpc $\leqslant \$ 1045$ and $\geqslant \$ 12,746$, respectively (fiscal year 2015) (World Bank, 2016a). The range of eligibility thresholds thus spanned almost the entire range of GNIpc for MICs. This variation reflects the current disagreement over the proper role of GNIpc in aid allocation. Related to this question of role is the question about what other measures and criteria should be combined with GNIpc. In particular, few argue that GNIpc correlates perfectly with need for DAH or countries capacity to provide health services without DAH. 
As indicated by Tables 1 and 2, there was considerable variation in what criteria accompanied GNIpc. Funders of DAH may carefully assess each of these in order to develop a package of criteria in which GNIpc is suitably embedded.

\section{Methodologies}

As for what the funders did not do or did not emphasise, there were at least three commonalities. None of the funders defined their allocation criteria directly on the basis of a health production function or a costing or budget methodology (Fan et al., 2014). While the former specifies the relationship between inputs in the terms of DAH and outcomes in the terms of health improvements, the latter estimates resources needed to achieve a given goal, for example, a certain level of health service coverage. While each of these approaches has its strengths, funders may avoid them because they are methodologically demanding and data hungry. In addition, these approaches may seem to leave funders with less flexibility in their decision making.

\section{Health indicators}

Funders not specifically devoted to health did typically not have specific criteria for $\mathrm{DAH}$, and many funders also lacked criteria directly related to health. This can be unfortunate because health state influences the overall need for assistance, and it may be particularly problematic for that part of development assistance whose primary purpose is to improve health. Several funders with a broad mandate provide large amounts of DAH, including IDA whose DAH reached $\$ 861$ million in 2013 (IHME, 2014). Funders of development assistance may thus look for criteria that take health properly into account, both for assistance directed towards improving health and for other kinds of assistance. These health-needs criteria can be disease-specific, like the disease-burden criteria used by GF, or more generic, like the U5MR criterion used by UNICEF, which covers a range of diseases but is restricted to children under five. For many funders, even more generic health-needs criteria may be most useful. In particular, it has been suggested that life expectancy and disability-adjusted life year rate perform well against the criteria of relevance, salience, validity, consistency, and timeliness and availability (Ottersen et al., 2016). At the same time, exactly how health-related criteria should differ from and interact with other types of criteria is still an open question and an important topic for future deliberation and research.

\section{Inequality indicators}

Another shared feature among the funders was the lack of criteria directly related to economic inequalities or to inequalities in health or health care. Criteria pertaining to inequality can be important because these criteria are sensitive to information often masked by country averages. Such criteria may be particularly relevant in the context 
of MICs, whose mid-level GNIpc often is combined with pronounced inequalities and substantial health needs (reference to paper on MICs by Ottersen, Moon and Rottingen in this series). At the same time, the role of inequality indicators in the allocation of DAH is tricky. One reason is that greater inequality may indicate greater capacity (Ceriani and Verme, 2013) and at the same time greater unmet needs, and these two may counteract each other. Inequality indicators are also associated with challenges related to incentives. If higher inequality implies more $\mathrm{DAH}$, countries have less incentive to promote equality (reference to paper on MICs by Ottersen, Moon and Røttingen in this series) (Basu et al., 2014). Funders that seek to introduce an inequality criterion may therefore consider linking it to other criteria that can help preserve such incentives (reference to paper on MICs by Ottersen, Moon and Røttingen in this series).

\section{Conclusion}

Recent changes in the landscape for DAH raise the fundamental question about what criteria promote fair and effective allocation of DAH across countries. This paper has reviewed the allocation criteria stated by 14 major funders of DAH. We found substantive similarities and differences, as well as gaps in the use of explicit criteria. The broad overview and these findings can assist funders and the global community in their search for better criteria.

\section{Acknowledgements}

The authors are grateful to the members of the Working Group on Health Financing at Chatham House Centre on Global Health Security and to Edward Anderson, Joseph Dieleman and Victoria Fan for their valuable comments. The authors also thank Eliane Furrer, Aurelia Nguyen, Ingvar Theo Olsen and Kumanan Rasanathan for their helpful responses to specific issues that arose in the preparation of this article.

\section{References}

Anderson, E. (2008), 'Practices and implications of aid allocation', Background Study for the 2008 Development Cooperation Forum, UN Economic and Social Council (ECOSOC).

Basu, S., D. Stuckler and M. McKee (2014), 'An alternative mechanism for international health aid: evaluating a global social protection fund', Health Policy and Planning, 29: 127-136.

Berthelemy, J.-C. (2006), "Bilateral donors' interest vs. recipients' development motives in aid allocation: do all donors behave the same?", Review of Development Economics, 10(2): 179-194.

BMZ (2013), 'The German Government's 14th Development Policy Report', Federal Ministry for Economic Cooperation and Development Germany, http://www.bmz.de/en/publications/ archiv/type_of_publication/information_flyer/information_brochures/Materialie223_ Weissbuch_large.pdf [24 June 2016]. 
BMZ (2014), 'German Development Cooperation Work', Federal Ministry for Economic Cooperation and Development Germany, http://www.bmz.de/en/publications/topics/ development_policy/Materialie239_ez.pdf [24 June 2016].

Brock, D. W. (2002), 'Priority to the Worse Off in Health-Care Resource Prioritization', in R. Rhodes, M. P. Battin and A. Silvers (eds), Medicine and Social Justice: Essays on the Distribution of Health Care, New York: Oxford University Press, 362-372.

Burgett, A., S. Orzell and R. Salvado (2016), 'Running from behind: global aid allocation and the new geography of poverty', DPAF Working Paper Series, Bill \& Melinda Gates Foundation.

Cagé, J. (2015), 'Improving upon the World Bank's country policy and institutional assessment: a new performance indicator based on aid effectiveness', Journal of Globalization and Development, 5(2): 213-233.

Ceriani, L. and P. Verme (2013), The Income Lever and the Allocation of Aid Research Working Paper No. WPS 6367. Washington, DC: World Bank Group: Society for the Study of Economic Inequality.

CEWG (2012), Research and Development to Meet Health Needs in Developing Countries: Strengthening Global Financing and Coordination'. Consultative Expert Working Group on Research and Development: Financing and Coordination, Geneva: World Health Organization.

Cogneau, D. and J.-D. Naudet (2007), 'Who deserves aid? Equality of opportunity, international aid, and poverty reduction', World Development, 35(1): 104-120.

Daniels, N. and J. E. Sabin (2008), Setting Limits Fairly: Learning to Share Resources for Health, 2nd edn, New York: Oxford University Press.

Department of State (2014), 'Congressional budget justification. Department of state, foreign operations, and related programs. Fiscal year 2015', http://www.usaid.gov/sites/default/ files/documents/9276/222898.pdf [8 March 2015].

DFAT (2014), 'Making performance count: enhancing the accountability and effectiveness of Australian aid', Department of Foreign Affairs and Trade, http:/www.dfat.gov.au/about-us/ publications/Documents/framework-making-performance-count.pdf [8 March 2015].

DFAT (2015), 'Health for Development Strategy 2015-2020', Department of Foreign Affairs and Trade, http://dfat.gov.au/about-us/publications/Documents/health-for-developmentstrategy-2015-2020.PDF [16 June 2016].

DFAT (2016), 'Australia's aid program', Department of Foreign Affairs and Trade, http://dfat.gov.au/aid/Pages/australias-aid-program.aspx [16 June 2016].

DFID (2011), Bilateral Aid Review: Technical Report, London: Department for International Development.

DFID (2015), 'UK aid: tackling global challenges in the national interest', UK Government, https://www.gov.uk/government/uploads/system/uploads/attachment_data/file/478834/ ODA_strategy_final_web_0905.pdf [23 June 2016].

EAI (2015), 'Updated - terms of reference for the Equitable Access Initiative', The Global Fund, http://www.theglobalfund.org/documents/eai/EAI_EquitableAccessInitiative_ToRs_en/ [28 June 2015].

EAI (2016), 'The Equitable Access Initiative', Final report, http://www.theglobalfund.org/ documents/eai/EAI_EquitableAccessInitiative_Report_en/ [14 January 2017].

Fan, V. Y., A. Glassman and R. L. Silverman (2014), 'How a new funding model will shift allocations from the Global Fund to Fight AIDS, tuberculosis, and malaria', Health Affairs, 33(12): 2238-2246.

Frenk, J., O. Gómez-Dantés and F. Chacón (2011), ‘Global health in transition', in R. Parker and M. Sommer (eds), Routledge Handbook in Global Public Health, New York: Routledge, 11-17. 
Frenk, J. and S. Moon (2013), 'Governance challenges in global health', New England Journal of Medicine, 368: 936-942.

GAC (2016), 'Where we work in International Development', Global Affairs Canada, http://www.international.gc.ca/development-developpement/countries-pays/index.aspx? lang=eng [16 June 2016].

Gavi (2013), 'Review of GAVI's pilot prioritisation mechanism. Report to the GAVI Alliance Board, 11-12 June 2013', Gavi, The Vaccine Alliance, http://www.gavi.org/ Library/GAVI-documents/Policies/GAVI-Alliance-Prioritisation-Mechanism/ [18 February 2015].

Gavi (2015a), 'Independent Review Committee review criteria for applications for all types of GAVI support 2016', Gavi, The Vaccine Alliance, http://www.gavi.org/library/ documents/gavi-documents/guidelines-and-forms/irc-review-criteria-for-2016/

Gavi (2015b), 'General guidelines for expressions of interest and applications for all types of GAVI support in 2016', Gavi, The Vaccine Alliance, http://www.gavi.org/library/ gavi-documents/guidelines-and-forms/ [31 May 2016].

Gavi (2015c), 'Country eligbility policy', http://www.gavi.org/about/governance/programmepolicies/country-eligibility/ [16 June 2015].

Gavi (2016a), 'Countries eligible for support', http://www.gavi.org/support/apply/countrieseligible-for-support/ [16 June 2016].

Gavi (2016b), 'Prioritisation mechanism', http://www.gavi.org/about/governance/programmepolicies/prioritisation/ [31 May 2016].

GF (2013), 'Terms of reference of the Technical Review Panel', The Global Fund to Fight AIDS, Tuberculosis and Malaria, http://www.theglobalfund.org/documents/trp/TRP_ TechnicalReviewPanel_ToR_en/ [18 February 2015].

GF (2016b), 'The Global Fund Eligibility Policy (GF/B35/06)', The Global Fund to Fight AIDS, Tuberculosis and Malaria, http://www.theglobalfund.org/documents/board/ 35/BM35_06-Eligibility_Policy_en/ [16 June 2016].

GF (2016c), 'The Challenging Operating Environments Policy (GF/B35/03)', The Global Fund to fight AIDS, Tuberculosis and Malaria, http://www.theglobalfund.org/documents/ board/35/BM35_03-ChallengingOperatingEnvironments_Policy_en/ [16 June 2016].

GF (2016d), 'The Global Fund Sustainability, Transition and Co-financing Policy (GF/B35/04)', The Global Fund to Fight AIDS, Tuberculosis and Malaria, http://www.theglobalfund.org/ documents/board/35/BM35_04-SustainabilityTransitionAndCoFinancing_Policy_en/. [16 June 2016].

GF (2016e), 'What the Technical Review Panel Looks for in a Concept Note', The Global Fund to Fight AIDS, Tuberculosis and Malaria, http://www.theglobalfund.org/ documents/trp/TRP_WhatTheTRPLooksForInAConceptNote_Paper_en/. [16 June 2016].

GF (2016f), 'Allocation Methodology 2017-2019 (GF/B35/05)', The Global Fund to Fight AIDS, Tuberculosis and Malaria, http://www.theglobalfund.org/documents/board/35/ BM35_05-AllocationMethodology2017-2019_Report_en/ [16 June 2016].

Gibson, C. C., K. Andersson, E. Ostrom and S. Shivakumar (2005), The Samaritan's Dilemma: The Political Economy of Development Aid, Oxford: Oxford University Press.

Gostin, L. O. (2014), Global Health Law, Cambridge, MA: Harvard University Press.

Guillaumont, P. (2008), 'Adapting aid allocation criteria to development goals', Essay for the 2008 Development Cooperation Forum.

IDA (2013), 'Annex 2. IDA's performance-based allocation system for IDA17', International Development Association, http://www.worldbank.org/ida/papers/Annex_2_IDA17.pdf [28 Feburary 2015]. 
IHME (2014), Financing Global Health 2013: Transition in an Age of Austerity, Seattle, WA: IHME.

IHME (2016), Financing Global Health 2015: Development Assistance Steady on the Path to New Global Goals, Seattle, WA: IHME.

Institute of Medicine (2013), Evaluation of PEPFAR, Washington, DC: The National Academies Press.

Knack, S., F. H. Rogers and J. C. Heckelman (2012), 'Crossing the threshold: a positive analysis of IBRD graduation policy', Review of International Organizations, 7: 145-176.

Koeberle, S., H. Bedoya, P. Silarszky and G. Verheyen (eds) (2005), Conditionality Revisited: Concepts, Experiences, and Lessons, Washington, DC: World Bank.

Leo, B. (2010), Inside the World Bank's Black Box Allocation System: How Well Does IDA Allocate Resources to the Neediest and Most Vulnerable Countries?, Washington, DC: Center for Global Development.

Llavador, H. G. and J. E. Roemer (2001), 'An equal-opportunity approach to the allocation of international aid', Journal of Development Economics, 64: 147-171.

LuxDev (2013), 'Vietnam', Luxembourg Agency for Development Cooperation, http://dak. luxdev.lu/files/documents/VIE_light.pdf [7 March 2015].

LuxDev (2015a), 'Annual Report 2014', Luxembourg Agency for Development Cooperation, https://luxdev.lu/files/documents/RAPANN2014_web_UK.pdf [23 June 2016].

LuxDev (2015b), 'Our activities', Luxembourg Agency for Development Cooperation, http://luxdev.lu/en/activities\#countries [23 June 2016].

MCC (2015a), 'Candidate country report', Millenium Challenge Corporation, https://www. mcc.gov/resources/doc/report-candidate-country-fy-2016 [23 June 2016].

MCC (2015b), 'Selection criteria and methodology report', https://www.mcc.gov/resources/ doc/report-selection-criteria-and-methodology-fy16 [23 June 2016].

MCC (2015c), 'About MCC', Millennium Challenge Corporation, https://www.mcc.gov/ pages/about [3 March 2015].

MCC (2016), 'Who We Fund - the Country Selection Process', Millenium Challenge Corporation, https://www.mcc.gov/who-we-fund [23 June 2016].

McGee, R. (2011), 'Aid transparency and accountability: 'build it and they'll come'?', Development Policy Review, 31(S1): s107-s124.

McGillivray, M. (2011), 'Aid allocation and fragile states', in W. Naudé, A. U. Santos-Paulino and M. McGillivray (eds), Fragile States: Causes, Costs, and Responses, New York: Oxford University Press, 166-185.

Ministry of Foreign Affairs Norway (2014a), 'Reforming development assistance to improve results', https://www.regjeringen.no/en/aktuelt/development_reform/ id2005626/ [16 June 2016].

Ministry of Foreign Affairs Norway (2014b), 'St. Prop. 1 (2014-2015) 10 Programområde 03 Internasjonal Bistand': R. N. M. o. Finance, http://www.statsbudsjettet.no/Statsbudsjettet2015/Dokumenter-NY/Fagdepartementenes-proposisjoner/Utenriksdepartementet-UD/ Prop-1-S/Del-1-Innledende-del-/10-Programomrade-03-Internasjonal-bistand/ [22 June 2016].

Ministry of Foreign Affairs Norway (2016), 'Utenrikspolitisk redegjørelse 1. mars 2016', https://www.regjeringen.no/no/aktuelt/redegjoerelse_160301/id2477557/

Moon, S. and O. Omole (2013), Development Assistance for Health: Critiques and Proposals for Change, London: Chatham House.

Moon, S. and T. Williamson (2010), Greater Aid Transparency: Crucial for Aid Effectiveness, Project Briefing, London: Overseas Development Institute. 
Norad (2014), 'Instruks for Direktoratet for Utviklingssamarbeid (Norad)', Ministry of Foreign Affairs, https://www.regjeringen.no/no/dokumenter/instruks_norad/id748340/ [22 June 2016].

Norad (2016), 'About Norad', https://www.norad.no/en/front/about-norad/ [22 June 2016].

Ooms, G., K. Derderian and D. Melody (2006), 'Do we need a world health insurance to realise the right to health?', PLoS Medicine, 3(12): e530.

Ottersen, T., A. Kamath, S. Moon and J.-A. Røttingen (2014), Development Assistance for Health: Quantitative Allocation Criteria and Contribution Norms, London: Chatham House.

Ottersen, T., K. Grépin, K. Henderson, C. B. Pinkstaff, C. Clift, O. F. Norheim and J.-A. Røttingen (2016), 'Health and Development: An Explicit Approach to the Design and Assessment of Country Classification Frameworks Final Report for the Equitable Access Initiative Oslo: Norwegian Institute of Public Health.

OWG (2014), 'Open Working Group proposal for Sustainable Development Goals', Open Working Group, https://sustainabledevelopment.un.org/content/documents/1579SDGs \%20Proposal.pdf [7 March 2015].

PEPFAR (2011), 'Fiscal year 2011: PEPFAR operational plan', The United States President's Emergency Plan for AIDS Relief, http://www.pepfar.gov/documents/organization/ 183974.pdf [14 January 2017].

PEPFAR (2015), 'PEPFAR Country/Regional Operational Plan (COP/ROP) 2016 Guidance', US Department of State, http://www.pepfar.gov/documents/organization/250377.pdf [16 June 2016].

Pietschmann, E. (2013), Assist Those Most in Need, or Most of Those in Need? The Challenge of Allocative Efficiency for Aid Effectiveness, Bonn: German Development Institute.

Resch, S., T. Ryckman and R. Hecht (2015), 'Funding AIDS programmes in the era of shared responsibility: an analysis of domestic spending in 12 low-income and middle-income countries', Lancet Global Health, 3: e52-e61.

Salvado, R. C. and J. Walz (2013), Aid Eligibility and Income Per Capita: A Sudden Stop for MICs? DPAF Working Paper Series Seattle: Bill \& Melinda Gates Foundation: Bill \& Melinda Gates Foundation.

Sumner, A. (2012), 'Where do the poor live?', World Development, 40(5): 865-877.

Temple, J. R. W. (2010), ‘Aid and conditionality', in D. Rodrik and M. Rosenzweig (eds), Handbook of Development Economics Volume 5 Amsterdam: North-Holland, 4415-4523.

UK Parliament (2016), 'UK aid: allocation of resources: interim report', House of Commons, International Development Committee.

UNDP (2011), 'Executive Board informal meeting. Information note on the 2008-2013 programming arrangements', United Nations Development Programme.

UNDP (2012a), 'Programming arrangements, 2014-2017', United Nations Development Programme, http://www.undp.org/content/dam/undp/library/corporate/Executive\% 20Board/2012/second-regular-session/English/dp2012-25.doc [16 June 2016].

UNDP (2012b), 'Second review of the programming arrangements, 2008-2013', United Nations Development Programme, http://www.undp.org/content/dam/undp/library/corporate/ Executive\%20Board/2012/first-regular-session/english/dp2012-3e.pdf [16 June 2016].

UNDP (2013b), 'Decisions adopted by the Executive Board in 2012', United Nations Development Programme, http://www.undp.org/content/dam/undp/library/corporate/ Executive\%20Board/2013/English/dp2013-2e.pdf [22 June 2016]. 
UNICEF (1997), 'Report on the allocation of general resources', United Nations Children's Fund. UNICEF (2012), 'Report on implementation of the modified system for allocation of regular resources for programmes', Item 5 of the provisional agenda, Second regular session 2012, Executive Board, United Nations Children's Fund.

UNICEF (2016), 'Regular resources', http://www.unicef.org/publicpartnerships/66662_66850. html\#Allocation_of_Regular_Resources_to_programme_countries [16 June 2016].

US Congress (2003), 'United States Leadership Against HIV/AIDS, Tuberculosis, and Malaria Act of 2003', H.R. 1298. 108th Congress.

US Congress (2008), 'Tom Lantos and Henry J. Hyde United States Global Leadership Against HIV/ AIDS, Tuberculosis, and Malaria Reauthorization Act of 2008', P.L. 110-293. 110th Congress.

USAID (2006), 'Policy framework for bilateral foreign aid: implementing transformational diplomacy through development', United States Agency for International Development, http://pdf.usaid.gov/pdf_docs/PDACG244.pdf [16 June 2016].

USAID (2011), 'The Nine Principles of Development', United States Agency for International Development, https://www.usaid.gov/sites/default/files/documents/1872/200mbn.pdf [14 January 2017].

USAID (2014), 'Ending preventable maternal mortality: USAID maternal health vision for action', United States Agency for International Development, http://www.usaid.gov/sites/ default/files/documents/1864/MCHVision.pdf [16 June 2016].

USAID (2015), 'Family planning program overview', United States Agency for International Development, https://www.usaid.gov/sites/default/files/documents/1864/FP-programoverview-508.pdf [23 June 2016].

Vázquez, S. T. (2015), 'Geographical Allocation of Aid: Lessons from Political Economy', in B. M. Arvin and B. Lew (eds), Handbook of the Economics Of Foreign Aid, Cheltenham: Edward Elgar Publishing, 90-108.

World Bank (2016a), 'World Bank GNI per capita operational guidelines \& analytical classifications', http://siteresources.worldbank.org/DATASTATISTICS/Resources/OGHIST. xls [1 July 2016].

World Bank (2016b), 'How IDA resources are allocated', World Bank, http://ida.worldbank. org/financing/resource-management [16 June 2016]. 